\title{
Immunohistochemical characterization of phagocytic immune cell infiltration into different adipose tissue depots of dairy cows during early lactation
}

\author{
S. H. Akter, ${ }^{\star} \dagger$ S. Häussler, ${ }^{* 1}$ D. Germeroth, ${ }^{\star}$ D. von Soosten,‡ S. Dänicke,‡ K.-H. Südekum,§ \\ and H. Sauerwein* \\ *Institute of Animal Science, Physiology and Hygiene Group, University of Bonn, 53115 Bonn, Germany \\ †Faculty of Veterinary Science, Department of Anatomy and Histology, Bangladesh Agricultural University, Mymensing-2202, Bangladesh \\ łInstitute of Animal Nutrition, Friedrich-Loeffler-Institute (FLI), Federal Research Institute for Animal Health, 38116 Braunschweig, Germany \\ §Institute of Animal Science, Animal Nutrition Group, University of Bonn, 53115 Bonn, Germany
}

\begin{abstract}
The present study aimed to investigate whether phagocytic immune cells infiltrate into bovine adipose tissue (AT) and to study the effects of lactation and conjugated linoleic acid (CLA) supplementation on the invasion of phagocytic immune cells into different s.c. and visceral (v.c.) fat depots of primiparous dairy cows during the first $105 \mathrm{~d}$ in milk (DIM). German HolsteinFriesian cows (HF; $\mathrm{n}=25)$ with a mean body condition score of 3.0 were divided into a control $(\mathrm{CON})$ and a CLA group. From 1 DIM until sample collection, CLA cows were fed $100 \mathrm{~g}$ of CLA supplement/d (about 6\% of $c 9, t 11$ and $t 10, c 12$ isomers each), whereas the $\mathrm{CON}$ cows received $100 \mathrm{~g} / \mathrm{d}$ of a fatty acid mixture instead of CLA. The CON cows $(\mathrm{n}=5$ each $)$ were slaughtered at 1,42 , and 105 DIM, and the CLA cows $(\mathrm{n}=5$ each $)$ were slaughtered at 42 and 105 DIM. Adipose tissues (n $=150$ ) from 3 s.c. (tailhead, withers, and sternum) and 3 v.c. (omental, mesenteric, and retroperitoneal) depots were sampled. In addition, s.c. tailhead biopsies were collected by repeated surgical biopsies (3 samplings within 7 wk; $\mathrm{n}=36$ ) from 12 nonpregnant, nonlactating Simmental heifers (SM; mean body condition score $=5.0$ ) fed diets of varying energy density to compare the changes in phagocytic immune cell infiltration with early lactating cows. Immunohistochemical analyses of different fat depots revealed a low incidence of phagocytic immune cell infiltration in early lactating cows. The portion of infiltrating macrophages (CD68+) in a few positive AT samples of HF cows was slightly lower in s.c. than v.c. fat and was positively correlated with both empty body weight and adipocyte size. However, no differences with regard to DIM and CLA supplementation were observed in HF cows. Increased accumulation of phagocytic immune cells, albeit at low cell numbers, in nonpregnant, over-conditioned SM heifers
\end{abstract}

Received August 22, 2011.

Accepted January 27, 2012

${ }^{1}$ Corresponding author: susanne.haeussler@uni-bonn.de might be related to larger adipocytes secreting higher amounts of chemoattractant adipokines compared with the early lactating cows. In conclusion, the extent of fatness in HF cows may not be high enough to stimulate significant infiltration of phagocytic cells in AT and, therefore, these immune cells might have no major role in the immunologic and metabolic adaptations of AT during early lactation.

Key words: adipose tissue, dairy cow, early lactation, immune cell infiltration

\section{INTRODUCTION}

During early lactation, dairy cows undergo coordinated metabolic adaptations, mainly due to the excessive energy demands imposed by the lactating udder (Bauman and Currie, 1980). The energy requirements at this period cannot entirely be met through dietary intake, which results in negative energy balance (NEB) and body fat mobilization. The dairy cow responds to NEB with a decrease in lipogenesis and an increase in lipolysis in the adipose tissue (AT; McNamara and Hillers, 1989). The rate of lipolysis shows considerable interindividual variation: in some cows, it well exceeds the needs for maintenance and milk synthesis and, thus, increases the risk for fatty liver and other health disturbances; in contrast, other cows can increase feed intake rapidly and lose significantly less body fat (McNamara, 2004). Besides its function as an energy storage depot, AT secretes endocrine factors that exert a dichotomic function both in metabolism and immunoregulation; AT thus forms a gateway connecting metabolism with innate immunity (Schäffler and Schölmerich, 2010). The major phagocytic cells of the innate immune system include neutrophils, monocytes, and macrophages, which originate from the myeloid progenitors in the bone marrow (Noorman et al., 1997; Weisberg et al., 2003). Neutrophils circulate in the blood and are readily attracted to sites of inflammation (Schymeinsky et al., 2007). Monocytes are also circulating cells, which eventually evade into tissues and differentiate into 
macrophages (Hume et al., 2002). These immune cells have the ability to phagocytize directly; among them, macrophages are highly effective phagocytes acting in innate immunity and tissue remodeling via cytokine secretion and apoptotic body clearance (Saillan-Barreau et al., 2003). Tissue macrophages can be identified via flow cytometry or immunohistochemical staining by their specific expression of several proteins including cluster of differentiation (CD)68, CD14, CD11b, and CD11c (Khazen et al., 2005). Protein CD68 is the main macrophage-specific marker; however, Noorman et al. (1997) reported that commonly used macrophage markers are also expressed on monocytes (CD14, CD11b, and CD11c) or on granulocytes (CD11b). In the context of obesity and high-fat diets, humans and rodents exhibit increased infiltration of AT macrophages (ATM), particularly in visceral (v.c.) depots to form a proinflammatory micromilieu, causing local and systemic insulin resistance (Weisberg et al., 2003; $\mathrm{Xu}$ et al., 2003). This phenomenon is associated with changing adipokine profiles and positively correlates with adipocyte size and body fat mass (Weisberg et al., 2003). Moreover, AT neutrophils transiently infiltrate before the infiltration of ATM in diet-induced obese mice (Elgazar-Carmon et al., 2008).

Conjugated linoleic acid (CLA) designates a group of naturally occurring dienoic derivatives of linoleic acid. Cis-9,trans-11 $(\boldsymbol{c 9 , t 1 1 )}$ is the predominant natural CLA isomer occurring exclusively in ruminant meat and milk, whereas commercially available CLA preparations contain this isomer together with the trans10,cis-12 (t10,c12) isomer in equimolar concentrations (Poirier et al., 2006). Isomers of CLA have a wide range of beneficial effects, such as anticarcinogenic, antiatherogenic, antidiabetic, and antiobesity effects (Bauman et al., 2001). Supplementation of dairy cows with CLA has recently been reported to decrease milk fat, but left body fat mostly unaffected in terms of depot mass (von Soosten et al., 2011). However, when considering adipocyte sizes, CLA-supplemented cows had smaller adipocytes both in s.c. and v.c. fat depots compared with control (CON) cows (Akter et al., 2011). Nevertheless, the $t 10, c 12$ isomer promotes ATM infiltration (Poirier et al., 2006), whereas the $c 9, t 11$ isomer decreases this phenomenon in mice (Moloney et al., 2007).

So far, most research on ATM infiltration has focused on their contribution to the development of obesityassociated pathologies through systemic effects in nonruminant species (Bouloumié et al., 2005; Schäffler and Schölmerich, 2010). To our knowledge, no report exists about phagocytic immune cell infiltration into bovine AT. We hypothesized that the number of phagocytic immune cells in AT of dairy cows would change during the lactation-induced metabolic alterations. Therefore, the present study aimed to investigate 1) whether phagocytic immune cells infiltrate into s.c. and v.c. fat depots of primiparous dairy cows during the first 105 DIM and 2 ) whether or not a dietary CLA supplement may affect this infiltration phenomenon. Immunohistochemistry was performed on AT cryosections to characterize the portion of CD68-, CD14-, CD11b-, and CD11c-positive cells in different fat depots of early lactating dairy cows. In addition, the changes in the portion of phagocytic immune cells in AT of early lactating cows were compared with nonpregnant, overconditioned heifers and old, fat steers.

\section{MATERIALS AND METHODS}

\section{Animals, Experimental Designs, and Diets}

The experimental design of the trials described below is illustrated in Figure 1.

Trial 1: Early Lactating Cows. The animal experiment was conducted according to the European Union guidelines and was approved by the Lower Saxony State Office for Consumer Protection and Food Safety (LAVES, Oldenburg, Germany; file number 33.11.42502-04-071/07). The details of this study have been described previously (von Soosten et al., 2011). In brief, German Holstein-Friesian $(\mathbf{H F})$ cows $(\mathrm{n}=25)$ with a mean BCS of 3.0 (scale $=1$ to 5 ) were housed in group pens in a freestall barn at the experimental station of the Institute of Animal Nutrition, FriedrichLoeffler-Institute (FLI, Braunschweig, Germany). Concentrate was provided via computerized concentrate feeding stations (type RIC; Insentec BV, Marknesse, the Netherlands) in each group pen. The animals were fed according to the recommendations of the German Society of Nutrition Physiology (GfE, 2001). Water was provided ad libitum. Before parturition, cows received a diet consisting of a partial mixed ration (PMR; 60\% corn silage and $40 \%$ grass silage on a DM basis; 6.7 MJ of $\mathrm{NE}_{\mathrm{L}} / \mathrm{kg}$ of $\mathrm{DM}$ ) for ad libitum intake and $2 \mathrm{~kg}$ of concentrate/d (6.7 MJ of $\mathrm{NE}_{\mathrm{L}} / \mathrm{kg}$ of $\left.\mathrm{DM}\right)$. After parturition, they were fed a PMR (25\% grass silage, $38 \%$ corn silage, and $37 \%$ PMR concentrate on a DM basis) for ad libitum intake (7.5 MJ of $\mathrm{NE}_{\mathrm{L}} / \mathrm{kg}$ of $\left.\mathrm{DM}\right)$. In addition, $3.5 \mathrm{~kg}$ of concentrate $\left(8.9 \mathrm{MJ}\right.$ of $\mathrm{NE}_{\mathrm{L}} / \mathrm{kg}$ of DM for CON cows and 8.7 MJ of $\mathrm{NE}_{\mathrm{L}} / \mathrm{kg}$ of $\mathrm{DM}$ for CLA cows), which contained the CON fat supplement or the CLA supplement, was provided by the concentrate feeding stations in pelleted form from parturition until slaughter.

The animals were randomly allocated to either the CON $(n=15)$ or the CLA $(n=10)$ group. From 1 DIM until sample collection, the CLA cows were fed $100 \mathrm{~g} / \mathrm{d}$ of a rumen-protected (lipid-encapsulation 
Trial 1: Early lactating Holstein cows $(n=25)$

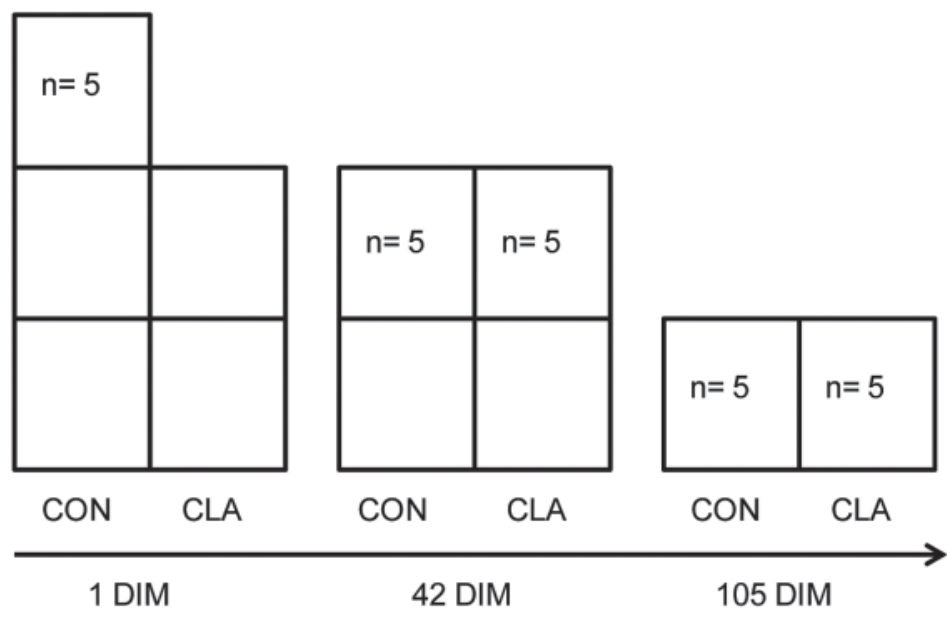

Trial 2: Nonpregnant, overconditioned Simmental heifers $(n=12)$

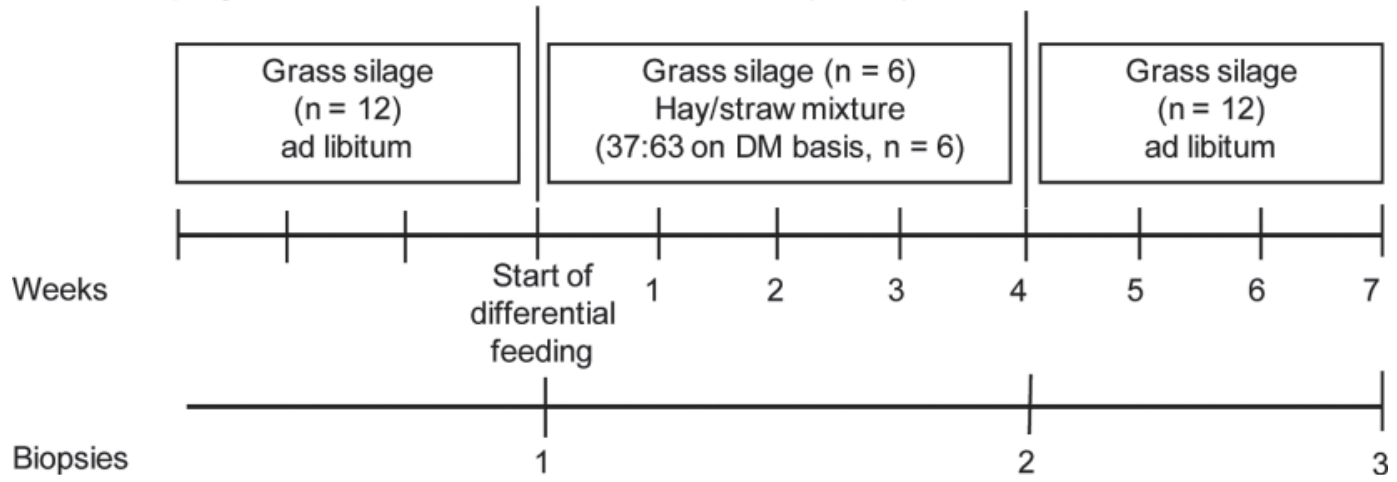

Figure 1. Experimental designs of trial 1 [early lactating Holstein cows fed diets of control (CON) and conjugated linoleic acid (CLA) supplements; $\mathrm{n}=25$ ] and trial 2 (nonpregnant, overconditioned Simmental heifers fed diets of varying energy density; $\mathrm{n}=12$ ). The animals from trial 1 slaughtered from the CON and the CLA groups at each sampling day $(\mathrm{n}=5)$ per group are depicted as hatched bar sections.

technique) CLA supplement (Lutrell Pure; BASF SE, Ludwigshafen, Germany) and the CON cows received $100 \mathrm{~g} / \mathrm{d}$ of a FA mixture (Silafat; BASF SE). The control fat supplement contained $87.3 \%$ stearic acid, $10.9 \%$ palmitic acid, and $<0.01 \%$ oleic acid. The CLA supplement contained $72 \%$ of these FA (10.9\% stearic acid, $50.3 \%$ palmitic acid, and $10.7 \%$ oleic acid) and approximately $12 \%$ each of the $t 10, c 12$ and $c 9, t 11$ isomers; the pelleted CLA concentrate contained about $6 \%$ each of the $t 10, c 12$ and $c 9, t 11$ isomers (calculated based on the analyzed proportion in concentrates; von Soosten et al., 2011). The CON cows $(\mathrm{n}=5$ each) were slaughtered at 1, 42, and 105 DIM, whereas the CLA cows $(\mathrm{n}=5$ each) were slaughtered at 42 and 105 DIM.

Trial 2: Nonpregnant, Overconditioned Heifers. The animal experiment was approved by the North Rhine-Westphalia State Agency for Nature, Environment, and Consumer Protection (LANUV-NRW, Reck- linghausen, Germany; file number 8.87.51.05.20.10.103). Adult, nonpregnant, nonlactating Simmental (SM) heifers $(\mathrm{n}=12)$ with a mean BCS of 5.0 (scale $=1$ to 5 ) were housed in a tie-stall barn bedded with straw at the Frankenforst experimental research farm of the Faculty of Agriculture, University of Bonn, Germany. The animals were fed with grass silage for ad libitum intake. To investigate the effects of a moderate weight loss, the heifers were allocated to 2 groups $(\mathrm{n}=6$ each) of similar mean BW $(692 \pm 43 \mathrm{~kg})$. One-half of the heifers were assigned to a ration in which grass silage was blended with a hay/straw mixture (ratio 37:63 on a DM basis), whereas the other animals remained on the grass silage diet. The grass silage contained $10.6 \%$ CP, $54.8 \%$ NDF (ash-free), and 34.6\% ADF (ash-free), and the hay/straw-silage mixture contained $8.5 \% \mathrm{CP}$, 63.2\% NDF (ash-free), and 37.0\% ADF (ash-free) on a DM basis. The estimated ME concentrations of the 
grass silage and hay/straw mixture were 9.5 and 8.1 $\mathrm{MJ} / \mathrm{kg}$ of DM, respectively. After $4 \mathrm{wk}$ of differential feeding, all animals were fed again with grass silage for further $3 \mathrm{wk}$. To avoid potential effects of divergent stages of the estrus cycle, all animals received a progesterone-releasing intravaginal device (PRID- $\alpha$; Ceva Santé Animale SA, Libourne, France) that was renewed every third week.

In addition, to assess the phagocytic immune cell infiltration in aged, fat gonadectomized cattle with high BW, s.c. tailhead fat biopsies $(\mathrm{n}=3)$ were sampled from three 13-yr-old, rumen-fistulated, fat German Red Pied (RP) steers, with a mean BW of $1,300 \mathrm{~kg}$. The animals were housed in a freestall barn at the Frankenforst experimental research farm. The animals had ad libitum access to pasture during summer and to medium quality grass silage during winter.

\section{Measurements and Tissue Sample Collection}

In trial 1, AT samples from 3 s.c. depots (tailhead, withers, and sternum) and from 3 v.c. depots (omental, mesenteric, and retroperitoneal fat) were collected immediately after slaughter. The mesenteric fat was collected from the fat around the jejunum and the retroperitoneal fat was sampled from the pararenal fat, located superficial to the renal fascia. The AT samples were then dissected and weighed. The empty BW (EBW) was calculated as the sum of the weights of all body parts, which were recorded during the slaughter process without claws cut off, ingesta, and contents of the urinary and gall bladder. For trial 2, s.c. tailhead fat samples $(\mathrm{n}=36)$ were collected by repeated surgical biopsies (1 sampling at the end of each the consistent grass silage feeding, the differing feeding, and the refeeding period) from the tailhead area according to the methods of Smith and McNamara (1989). In brief, after cleaning and disinfecting the sampling area and local lumbar anesthesia with $2 \%$ procaine hydrochloride (Procasel 2\%, Selectavet; Dr. Otto Fischer, Weyarn-Holzolling, Germany), s.c. fat biopsy was excised through a 5-cm incision from the base of the tail. Subcutaneous tailhead fat biopsies were collected from RP steers following the same method. All of the tissue samples were then cut into small pieces (approximately $1 \mathrm{~cm}^{3}$ ), rinsed in $0.9 \%$ sodium chloride and immediately snap frozen in liquid nitrogen. They were transported on dry ice to the laboratory and then stored at $-80^{\circ} \mathrm{C}$ until analyses.

Blood samples were collected via jugular venipuncture and centrifuged to analyze serum concentrations of leptin using ELISA, according to Sauerwein et al., (2004). From the HF cows, blood samples $(\mathrm{n}=165)$ were collected in weekly intervals from 4 wk before until $4 \mathrm{wk}$ after calving and were limited thereafter to the tissue sampling days (i.e., 42 and 105 DIM). From the SM heifers, blood samples $(\mathrm{n}=96)$ were collected weekly throughout the 8 -wk observation period.

\section{Immunohistochemical Analyses}

Adipose tissue cryosections $(14-18 \mu \mathrm{m})$ were cut on a cryostat (Leica Mikrosysteme Vertrieb $\mathrm{GmbH}$, Wetzlar, Germany), mounted on SuperFrost Plus slides (Gerhard Menzel GmbH, Braunschweig, Germany) and stored at $-20^{\circ} \mathrm{C}$ until further staining. Frozen tissue sections were fixed in a chloroform-methanol mixture (AppliChem GmbH, Darmstadt, Germany; 1:1, vol:vol) at room temperature $\left(\mathbf{R T} ; 22^{\circ} \mathrm{C}\right)$ for $4 \mathrm{~h}$; the mixture was stored at $-20^{\circ} \mathrm{C}$ before use. After blocking endogenous peroxidase activity with $0.3 \%$ hydrogen peroxide (Carl Roth GmbH \& Co. KG, Karlsruhe, Germany) in methanol at RT for $15 \mathrm{~min}$, the sections were incubated with normal goat serum at a dilution of 1:10 at RT for 20 min to block nonspecific binding. The sections were then incubated with the primary monoclonal antibodies $(\mathbf{m A b})$ at $4^{\circ} \mathrm{C}$ overnight, as listed in Table 1 . The $\mathrm{mAb}$ against CD68 was detected by a secondary peroxidasecoupled goat anti-mouse antibody (DakoCytomation, Glostrup, Denmark), whereas the mAb against CD14, CD11b, and CD11c were detected with a biotinylated secondary goat anti-mouse antibody (SouthernBiotech, Birmingham, AL) in PBS at a dilution of 1:200 at RT for $30 \mathrm{~min}$. After incubating the slides with the biotinylated secondary antibody, the sections were additionally incubated with horseradish peroxidase-conjugated streptavidin (SouthernBiotech) at a dilution of 1:1000 (1:1600 for CD14) at RT for 30 min. Antigen-antibody complexes were visualized by 3-amino-9-ethylcarbazole (Biozol GmbH, Eching, Germany). The sections were counterstained with Mayer's hematoxylin and mounted with Kaiser's glycerol gelatine (both from Merck KGaA, Darmstadt, Germany). Bovine lymph node samples were used as positive and negative controls to the entire procedure to test specificity of immunostaining. The sections used as negative controls were incubated with PBS instead of the primary mAb.

\section{Histoplanimetry}

Bright-field pictures were taken from 10 representative fields per sample at $100 \times$ magnification using a Leica DMLB microscope (Leica Mikrosysteme Vertrieb $\mathrm{GmbH}$ ) and JVC digital color camera KY-F75U (Hachioji Plant of Victor Co., Tokyo, Japan). Adipocyte areas $\left(\mu \mathrm{m}^{2}\right)$ were measured as described previously 
Table 1. Primary mouse monoclonal antibodies used in this study

\begin{tabular}{llllll}
\hline Target & Clone & Source & Dilution & Specificity & Reference \\
\hline CD68 (human) & EBM11 & $\begin{array}{l}\text { DakoCytomation, } \\
\text { Glostrup, Denmark }\end{array}$ & $1: 100$ & Macrophages & Bielefeldt-Ohmann et al. (1988) \\
CD14 (bovine) & CAM36A & VMRD Inc., Pullman, WA & $1: 100$ & $\begin{array}{l}\text { Macrophages, } \\
\text { monocytes } \\
\text { Cacrophages, }\end{array}$ & Miyazawa et al. (2006) \\
CD11b (canine) & CA16.3E10 & Biozol GmbH, Eching, Germany & $1: 25$ & $\begin{array}{l}\text { monocytes, } \\
\text { granulocytes }\end{array}$ & Macrophages, \\
CD11c (bovine) & BAQ153A & VMRD Inc. & $1: 25$ & Miyazawa et al. (2006) \\
\hline
\end{tabular}

(Akter et al., 2011). The numbers of immunopositive cells and adipocytes per $\mathrm{mm}^{2}$ were counted (10 fields/ sample) using a grid $(900 \times 700 \mu \mathrm{m})$ with an image analysis software (DISKUS version 4.0; Carl H. Hilgers-Technisches Büro, Königswinter, Germany). The portion of CD68+ cells for each sample was calculated as the sum of the number of CD68+ cells divided by the total number of cells per section and then multiplied by 100 . The same procedure was used to calculate the portion of $\mathrm{CD} 14+, \mathrm{CD} 11 \mathrm{~b}+$, and $\mathrm{CD} 11 \mathrm{c}+$ immune cells in different AT depots. For the CD68 immunostaining, 150 samples (from $25 \mathrm{HF}$ cows) were tested. However, for the detection of additional CD14, CD11b, and CD11c markers in HF cows, 6 AT samples were taken from 2 cows per group at 1, 42, and 105 DIM (n $=60$ ), including 9 CD68-positive samples. In addition, these markers were also used for the remaining 1 CD68positive sample belonging to a cow at 1 DIM (in total, $\mathrm{n}=61)$.

\section{Statistical Analyses}

Data for all variables were tested for normal distribution with the Kolmogorov-Smirnov test and for homogeneity of variances with Levene's test. The Student's $t$-test was used to analyze the differences between the adipocyte sizes of HF cows and SM heifers; differences were considered significant at $P<0.05$. Pearson correlation was used to examine the relationship between the portion of CD68+ cells with both EBW and adipocyte size. All analyses were done using SPSS 19.0 (SPSS Inc., 2010). Values are given as means \pm standard errors of the means.

\section{RESULTS}

The hypothesis of the present study was that the amounts of phagocytic immune cells in AT of dairy cows would change during the first $100 \mathrm{~d}$ of lactation. To identify and quantify these immune cells in AT, sections were immunohistochemically stained by using
mAb against CD68, CD14, CD11b, and CD11c. Immunopositive cells were found in only few samples of $\mathrm{HF}$ cows during the first 105 DIM. Macrophages (CD68+) were immunolocalized as uniformly small, isolated cells around the cytoplasm of mature adipocytes. The same staining patterns were observed for CD14, CD11b, and CD11c; however, in contrast to CD68 staining, most of the positive cells were observed in the stromal-vascular fraction (SVF) rather than around adipocytes. Representative pictures of the $\mathrm{CD} 68, \mathrm{CD} 14, \mathrm{CD} 11 \mathrm{~b}$, and CD11c. staining in s.c. fat depots with corresponding positive and negative controls (bovine lymph nodes) are shown in Figure 2.

\section{Immune Cell Infiltration into AT of Early Lactating Cows}

CD68. Protein CD68 is the main cell surface marker of macrophages. With the exception of 10 samples from 8 cows, no ATM-positive staining was observed in the remaining 140 samples (Table 2). The average portion of CD68+ ATM in the few positive samples was slightly but insignificantly lower in s.c. depot $(3.7 \pm 0.7 \%, \mathrm{n}=$ $3)$ than in v.c. $\operatorname{depot}(24.7 \pm 5.2 \%, \mathrm{n}=7)$.

CD14. Protein CD14 is used as a marker of macrophages and monocytes. The immunostaining was positive in 1 out of 61 samples. The portion of CD14+ immune cells was $2.0 \%$ in this s.c. tailhead depot (Table $2)$.

$C D 11 b$. Protein CD11b is used as a marker of granulocytes and macrophages. The immunostaining was positive in 8 (out of 61 ) samples from 6 cows, among which 5 animals were coincidently immunopositive for CD68 (Table 2). The average portions of CD11b+ immune cells in the positive samples were $1.9 \pm 0.6 \%$ (n $=3)$ and $1.6 \pm 0.7 \%(\mathrm{n}=5)$ in s.c. and v.c. depots, respectively.

CD11c. Protein CD11c is commonly used as a marker of macrophages and monocytes. With the exception of 2 samples from 1 cow, no CD11c-positive staining was observed in the remaining 59 samples. The 


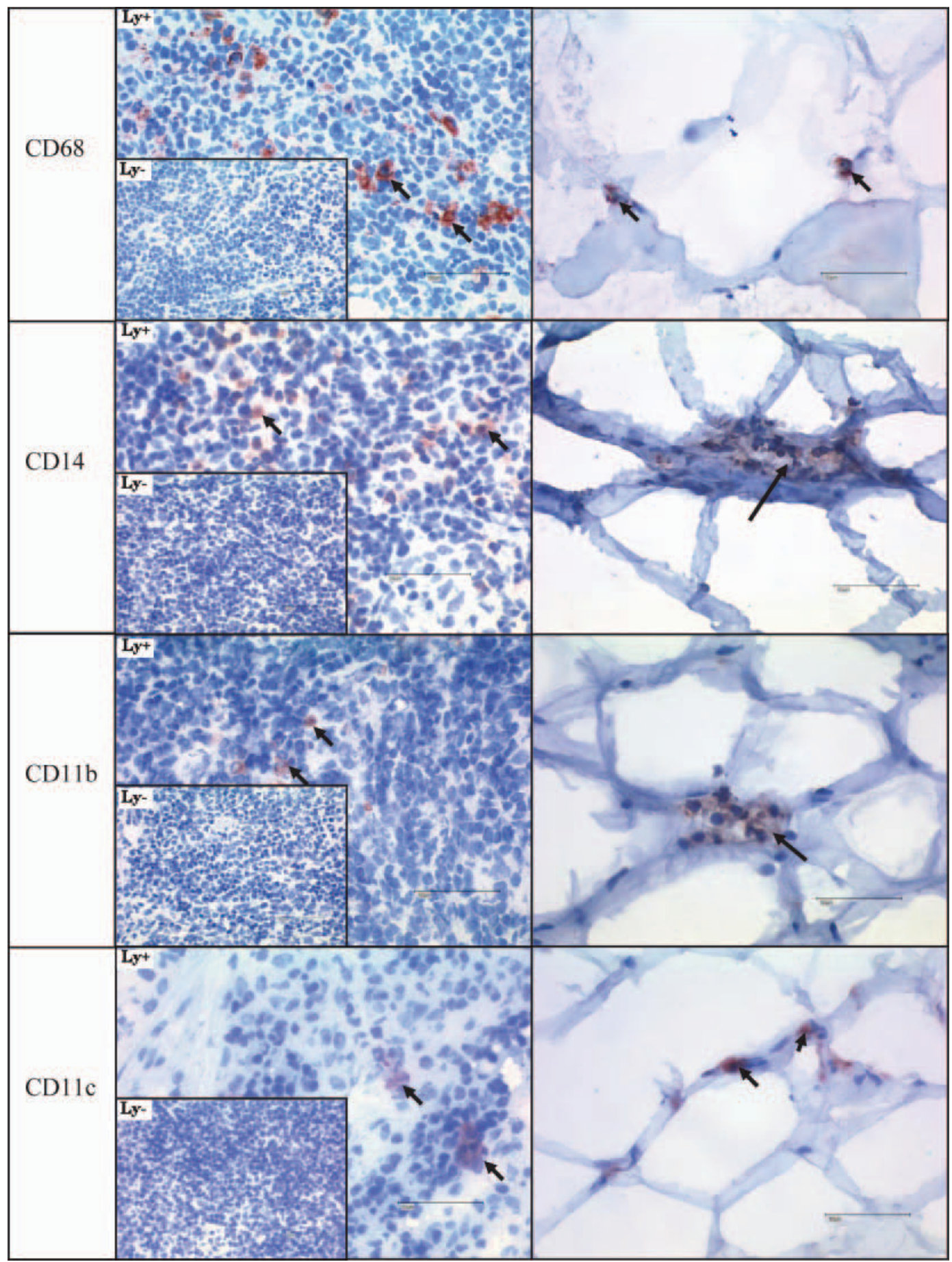

Figure 2. Immunohistochemical localization of CD68+, CD14+, CD11b+, and CD11c+ cells in the s.c. fat of early lactating Holstein cows (right column) with corresponding bovine lymph node tissue as positive (Ly+) and negative (Ly-) controls (left column). Representative positive cells (arrows) appear as red staining. Original magnification was $400 \times$. Scale bar $=50 \mu \mathrm{m}$.

average portion of CD11c+ immune cells in the positive samples was $3.7 \pm 1.7 \%(\mathrm{n}=2)$. The s.c. depot from the tailhead and sternum, but not the v.c. depot showed positive signal for this marker. These 2 samples were also immunopositive for CD68.

\section{Effects of Lactation and CLA Supplementation on the Invasion of Immune Cells into Bovine AT}

A total of 9 animals showed positive immunostainings in a few positive AT depots, irrespective of DIM 
Table 2. Portion (\%) of positive cells expressing CD68, CD14, CD11b, and CD11c markers in different fat depots of Holstein cows during the first 105 DIM $^{\mathrm{T}}$

\begin{tabular}{|c|c|c|c|c|}
\hline Item & Marker & $1 \mathrm{DIM}$ & 42 DIM & 105 DIM \\
\hline \multicolumn{5}{|c|}{ Control group $(\mathrm{n}=15)$} \\
\hline \multicolumn{3}{|c|}{ s.c. depot } & - & - \\
\hline \multirow{3}{*}{ Tailhead } & CD14 & - & - & - \\
\hline & CD11b & - & - & - \\
\hline & CD11c & - & - & - \\
\hline \multirow[t]{4}{*}{ Withers } & CD68 & - & $4.5(657)$ & - \\
\hline & CD14 & - & - & - \\
\hline & CD11b & - & - & $1.8(647)$ \\
\hline & CD11c & - & - & - \\
\hline \multirow[t]{4}{*}{ Sternum } & CD68 & - & - & - \\
\hline & CD14 & - & - & - \\
\hline & CD11b & - & - & $0.7(647)$ \\
\hline & CD11c & - & - & - \\
\hline \multicolumn{5}{|c|}{ Visceral (v.c.) depot } \\
\hline \multirow[t]{4}{*}{ Omental } & CD68 & $14.3(635)$ & $12.8(657)$ & - \\
\hline & CD14 & - & - & - \\
\hline & CD11b & $\begin{array}{l}0.7(635) \\
4.7(664)\end{array}$ & - & - \\
\hline & CD11c & - & - & - \\
\hline \multirow[t]{4}{*}{ Mesenteric } & CD68 & $\begin{array}{l}41.6(619), \\
27.2(664)\end{array}$ & - & - \\
\hline & CD14 & - & - & - \\
\hline & CD11b & $0.4(664)$ & - & - \\
\hline & CD11c & - & - & - \\
\hline \multirow[t]{4}{*}{ Retroperitoneal } & CD68 & - & - & $46.8(647)$ \\
\hline & CD14 & - & - & - \\
\hline & CD11b & - & - & $\begin{array}{l}0.8(640), \\
1.5(647)\end{array}$ \\
\hline & CD11c & - & - & - \\
\hline \multicolumn{5}{|c|}{ Conjugated linoleic acid group $(\mathrm{n}=10)$} \\
\hline \multirow{5}{*}{$\begin{array}{l}\text { s.c. depot } \\
\text { Tailhead }\end{array}$} & & & & \\
\hline & CD68 & & $2.0(668)$ & - \\
\hline & CD14 & & $2.0(668)$ & - \\
\hline & CD11b & & $3.3(668)$ & - \\
\hline & CD11c & & $1.2(668)$ & - \\
\hline \multirow[t]{4}{*}{ Withers } & CD68 & & - & - \\
\hline & CD14 & & - & - \\
\hline & CD11b & & - & - \\
\hline & CD11c & & - & - \\
\hline \multirow[t]{4}{*}{ Sternum } & CD68 & & $4.7(668)$ & - \\
\hline & CD14 & & - & - \\
\hline & CD11b & & - & - \\
\hline & CD11c & & $6.3(668)$ & - \\
\hline \multicolumn{5}{|l|}{ v.c. depot } \\
\hline \multirow[t]{4}{*}{ Omental } & CD68 & & - & $7.2(655)$ \\
\hline & CD14 & & - & - \\
\hline & CD11b & & - & - \\
\hline & $\mathrm{CD} 11 \mathrm{c}$ & & - & - \\
\hline \multirow[t]{4}{*}{ Mesenteric } & CD68 & & - & - \\
\hline & CD14 & & - & - \\
\hline & CD11b & & - & - \\
\hline & CD11c & & - & - \\
\hline \multirow[t]{4}{*}{ Retroperitoneal } & CD68 & & $23.2(666)$ & - \\
\hline & CD14 & & - & - \\
\hline & CD11b & & - & - \\
\hline & CD11c & & - & - \\
\hline
\end{tabular}

${ }^{1}$ To allow for tracing back individual positive samples, the respective individual animal identification numbers are given in parentheses following the portion.

and CLA supplementation (Table 2). No positive staining was found in any of the s.c. depots of CON cows at 1 DIM. For the v.c. depots, positive staining both for the CD68 and the CD11b markers were detected coin- cidently in omental and mesenteric fat in $2 \mathrm{CON}$ cows of 1 DIM. At 42 DIM, 2 CD68+ samples were found both in one s.c. depot (withers) and in the omental fat from the same CON cow. At 105 DIM, 1 positive 
Table 3. Portion (\%) of immune cells in the s.c. tailhead fat in early lactating primiparous Holstein-Friesian (HF) cows, nonpregnant, overconditioned Simmental (SM) heifers, and in fat Red Pied (RP) steers (means \pm SEM)

\begin{tabular}{lcccc}
\hline & \multicolumn{4}{c}{ Protein marker } \\
\cline { 2 - 5 } Item & CD68 & CD14 & CD11b & CD11c \\
\hline HF cows $(\mathrm{n}=25)$ & $2.0(\mathrm{n}=1)^{1}$ & $2.0(\mathrm{n}=1)^{1,2}$ & $3.3(\mathrm{n}=1)^{1,2}$ & $1.2(\mathrm{n}=1)^{1,2}$ \\
SM heifers $(\mathrm{n}=36)$ & $1.9 \pm 0.4(\mathrm{n}=23)$ & $1.7 \pm 0.4(\mathrm{n}=17)$ & $2.2 \pm 0.6(\mathrm{n}=12)$ & $2.1 \pm 0.7(\mathrm{n}=21)$ \\
RP steers $(\mathrm{n}=3)$ & - & $2.5 \pm 0.8(\mathrm{n}=3)$ & $2.1(\mathrm{n}=1)$ & - \\
\hline
\end{tabular}

${ }^{1}$ Indicates the tissue sample coincidently from same animal (animal identification number 668).

${ }^{2}$ Indicates $\mathrm{n}=10$ from early lactating $\mathrm{HF}$ cows were tested.

CD68 staining in the retroperitoneal fat and 3 positive CD11b immunostainings in s.c. fat from the withers, sternum, and in the retroperitoneal fat were observed in the same CON cow. Considering CLA supplementation, 4 positive immunostainings for the CD68, CD14, CD11b, and CD11c markers in the s.c. depot from the tailhead and 2 positive immunostainings for the CD68 and CD11c markers in the s.c. depot from the sternum were detected coincidently in the same CLA-fed cow at 42 DIM. However, no differences with regard to either DIM or CLA supplementation were observed in the few positive samples for all of the immunostainings.

\section{Comparison of the Portion of Phagocytic Immune Cells in AT from Early Lactating Cows, Nonpregnant, Overconditioned Heifers, and Fat Steers}

We herein found that the average portions of ATM $(\mathrm{CD} 68+)$ in the s.c. tailhead depot were only marginal both in nonpregnant SM heifers and the early lactating HF cows (Table 3), although the adipocyte size of this depot was larger in SM heifers than in HF cows $(P<$ $0.001)$, with mean areas of $8,230 \pm 240 \mu \mathrm{m}^{2}(\mathrm{n}=36)$ and $5,130 \pm 271 \mu \mathrm{m}^{2}(\mathrm{n}=25)$, respectively. However, no significant effect of differential feeding was observed in the SM heifers. The portion of CD68+ samples (s.c. tailhead) in the SM heifers (64\%; i.e., 23 out of 36 samples) was 16 times higher than in the corresponding depot from the HF cows (4\%; i.e., 1 out of 25 samples). Moreover, only $10 \%$ of the samples showed positive signals for each of the CD14, CD11b, and CD11c markers in HF cows, whereas they were 47, 33, and $58 \%$, respectively, in SM heifers (Table 3). However, the adipocyte size of s.c. tailhead fat depot was numerically larger in fat RP steers compared with the HF cows, with mean areas of $10,598 \pm 208 \mu^{2}(\mathrm{n}=3)$ and $5,130 \pm 271 \mu \mathrm{m}^{2}(\mathrm{n}=25)$, respectively. In RP steers, no CD68 and CD11c positive staining was observed in the s.c. tailhead depot, whereas the portion of CD14+ and CD11b+ samples was 100 and 33\%, respectively.

\section{Correlations Between the Portion of ATM (CD68+) with EBW and Adipocyte Size}

To investigate the relationship between the portion of ATM (CD68+) in positive samples with EBW and adipocyte size in HF cows, we calculated the correlations. Strong positive correlations were found between the portion of ATM with both EBW ( $\mathrm{r}=0.788, P=$ $0.007, \mathrm{n}=10)$ and mean adipocyte area $(\mathrm{r}=0.684$, $P=0.029, \mathrm{n}=10)$. Data collected from the 10 positive samples, out of 150 analyzed, are shown in Figure 3. Some samples comprising large adipocytes still did not show a positive signal for CD68 marker. However, no significant relationships were detectable between the portion of ATM and adipocyte size in s.c. tailhead depots from the SM heifers.

\section{DISCUSSION}

In the present study, different fat depots of dairy cows were characterized in terms of the number of phagocytic immune cells present therein. In this context, metabolic adaptation to early lactation and dietary CLA-related changes was of particular interest. For identifying phagocytic immune cells in AT, we used mAb directed against CD markers (i.e., CD68, CD14, CD11b, and CD11c) that are surface markers for monocytes, macrophages, and granulocytes (neutrophils). We herein present immunohistochemical evidence against an appreciable infiltration of phagocytic immune cells in bovine s.c. and v.c. fat depots. Several previous reports have been presented with regard to the localization and distribution of such cells in AT of obese mice and humans by using various mAb (Weisberg et al., 2003; Xu et al., 2003; Curat et al., 2004; Cinti et al., 2005; Elgazar-Carmon et al., 2008). In the context of obesity and high-fat diets, macrophages are one of the most prominent infiltrating cell types into AT. Most research on ATM infiltration in monogastric species is limited to obese individuals; however, early lactating cows are 
a

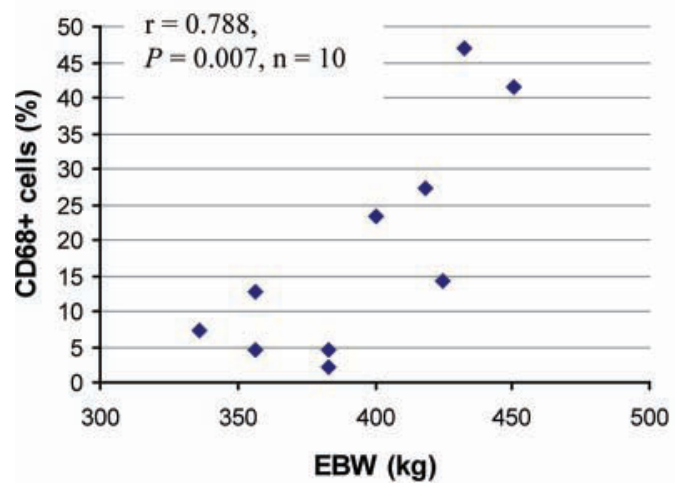

b

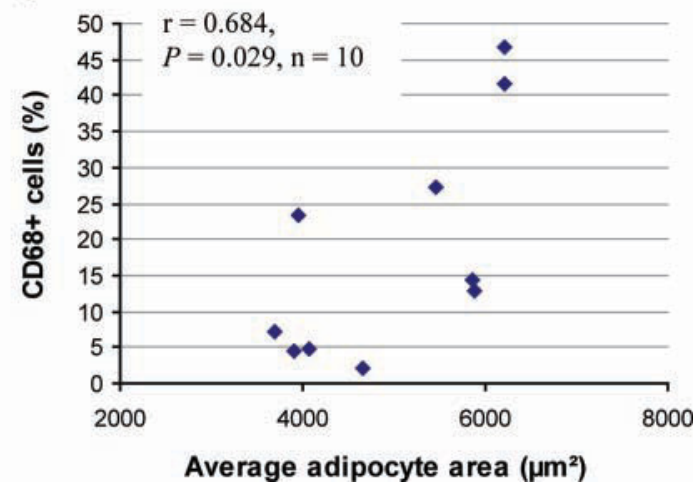

Figure 3. Correlations between the portion of CD68+ cells with a) empty body weight (EBW) and b) adipocyte size. Data included herein were collected from all positive immunostained samples of early lactating Holstein cows. Color version available in the online PDF.

not obese and may, thus, lack significant infiltration of macrophages into different AT depots.

We herein characterized specific immunohistological features of infiltrating macrophages in different bovine AT depots. In early lactating cows, the sparsely observed CD68+ macrophages were mostly localized around mature adipocytes. They probably correspond to the number of resident ATM that may eventually respond to local inflammation. This finding is similar to the study of infiltrating macrophages into the s.c. fat in lean humans (Cancello et al., 2005). The ATM of early lactating cows were uniformly small, isolated, and dispersed among the adipocytes. This observation agrees with the study of infiltrating macrophages into the s.c. fat of lean mice (Weisberg et al., 2003). In contrast, ATM localize to crown-like structures around individual adipocytes in v.c. fat both in lean and obese mice, which increase in frequency with obesity (Cinti et al., 2005). These structures were also found within the s.c. and v.c. fat in human obese patients, but were less frequent than in mice (Cancello et al., 2005; Zeyda et al., 2007).

\section{Evidence Against an Appreciable Infiltration of Phagocytic Immune Cells into Bovine AT During Early Lactation}

It is well known that metabolic adaptations in bovine AT form a critical part in establishing and maintaining lactation (Smith and McNamara, 1990; McNamara, 2010). During early lactation, the state of NEB contributes to the immunocompromised situation in dairy cows and, thus, leads to increased susceptibility to infectious diseases. In the present study, a low incidence of infiltrating phagocytic immune cells was observed in different fat depots of primiparous dairy cows during the first 105 DIM. We herein found that the portion of the
CD68+ samples was $6.6 \%$ in HF cows. Although CD68 is the main cell surface marker for macrophages, some other additional known macrophages markers have been reported to be expressed on monocytes (CD14, CD11b, and CD11c) or on granulocytes (CD11b). Therefore, CD14, CD11b, and CD11c markers were combined in the present study and the portions of positive samples were $1.6,13$, and $3.3 \%$, respectively. Weisberg et al. (2003) estimated that the portion of ATM ranges from under $10 \%$ in lean mice to over $50 \%$ in extremely obese, leptin-deficient mice, where AT depots from all mice contained F4/80-expressing cells (macrophages). However, in the present study, only $32 \%$ of the cows showed marginal infiltration of CD68+ ATM in different fat depots of early lactating HF cows, irrespective of DIM and CLA supplementation. Moreover, we found that the average portion of CD68+ ATM was numerically higher in v.c. than in s.c. depots, which is in agreement with other studies in obese mice (Weisberg et al., 2003) and humans (Harman-Boehm et al., 2007). This may be due to the fact that v.c. fat is more metabolically active and is thought to differ from s.c. fat in terms of adipokine production (Altomonte et al., 2003). The differences in the local production of chemokines may account for such a discrepancy (Skurk et al., 2005). This is in line with the view that adipocytes found in different depots have different properties (Cartwright et al., 2007). Moreover, recent evidence suggested that lipolysis can induce ATM recruitment in mice, as evidenced by increased ATM numbers coinciding with the peak in circulating concentrations of NEFA and, thus, AT lipolysis (Kosteli et al., 2010). In the present study, we did not observe any effect of DIM on the invasion of phagocytic immune cells into bovine AT (Table 2). Herein, active ongoing lipolysis, as evidenced by higher plasma NEFA concentrations, was limited to the first sampling at 1 DIM in early lactating HF cows (Akter et 
al., 2011) and its concentrations started to rise about 1 wk before calving, as reported in the companion paper (von Soosten et al., 2011). However, due to the experimental design, an exact time course of short-term invasion of ATM between 1 and 42 DIM cannot be provided. Therefore, it could be possible that we missed a short-term invasion of ATM population in the week after calving.

Immunohistochemical analyses of different s.c. and v.c. fat depots revealed that the portion of CD68+ ATM (from 10 positive samples out of 150 analyzed) was positively correlated with both EBW and adipocyte size. The positive linear correlation found between adipocyte size and CD68+ ATM suggests that large adipocyte size probably triggers macrophage infiltration. However, macrophage motility is characterized by its ability to respond to chemokine gradients emanating from AT (Gruen et al., 2007; described in the next section). In mice, ATM content in s.c., perigonadal, perirenal, and mesenteric depots correlates positively with criteria for adiposity such as body mass index, percent body fat, and adipocyte size (Weisberg et al., 2003). A similar positive correlation has been observed between ATM content in human s.c. fat depot and adiposity (Curat et al., 2004).

\section{Mechanisms of Infiltration of Phagocytic Immune Cells into AT}

The mechanism behind the migration of phagocytic immune cells into AT is not well clarified. It is thought that with the expansion of AT during weight gain, induction of a range of signaling pathways activates the adipose SVF, allowing monocytes to extravasate through the endothelial cell layer into the AT, where they differentiate into macrophages. These macrophages localize predominantly around dead adipocytes (Neels and Olefsky, 2006). Several reports suggest that the diverse biological activity of macrophages is mediated by functionally distinct subpopulations that are phenotypically polarized by their microenvironment and by exposure to inflammatory mediators. These divergent ATM subpopulations are broadly classified into 2 major groups: classically activated M1-type and alternatively activated M2-type macrophages. The M1 types are induced by inflammatory agents, whereas M2 types are induced by IL-4 and IL-13 (Zeyda et al., 2007). The M1-type macrophages display a cytotoxic, proinflammatory phenotype, whereas M2-type macrophages suppress immune and inflammatory responses and participate in wound repair and angiogenesis (Laskin, 2009). The ATM phenotypically resemble the antiinflammatory M2 type of macrophage in humans and mice (Zeyda and Stulnig, 2007). The changes in the expression of pro- and antiinflammatory factors after weight loss in obese individuals have been associated with a shift in the activation type of the tissue resident macrophages from the M1-type to M2-type macrophages (Clément et al., 2004). However, metabolic changes of AT in obesity may stimulate chemokine production, contributing to macrophage infiltration into AT (Wellen and Hotamisligil, 2005). On a quantitative basis, the vast majority of these chemokines come from the SVF of AT (Fain, 2006). For example, ATM produce the majority of TNF- $\alpha$ in AT, when compared with adipocytes or other cells in the SVF (Weisberg et al., 2003), and TNF- $\alpha$ expression increases with obesity (Hotamisligil et al., 1993). In s.c. fat of dairy cows, the mRNA abundance of TNF- $\alpha$ is higher at 1 DIM and at wk 5 postpartum, compared with wk 8 antepartum (Sadri et al., 2010).

Surface marker characteristics of ATM are important for their quantification. Most experimental data on AT inflammation originate from mouse experiments and, in general, F4/80-expressing cells in AT are referred to as ATM. Murine ATM have been shown to be CD14 negative and CD11c has been found particularly as a marker for diet-induced obesity-associated inflammatory macrophages (M1-type) in murine AT (Lumeng et al., 2007), whereas CD206, CD209, and CD163 are well-known M2 markers (Mantovani et al., 2002; Gordon and Taylor, 2005). Human ATM differ from murine ATM by expressing CD14; however, CD11c is only poorly expressed on human ATM (Curat et al., 2004; Zeyda et al., 2007). In the present study, 58\% of samples showing positive signals for CD11c in s.c. fat of nonpregnant, overconditioned SM heifers, might represent the M1 type of macrophages.

In our previous report (Akter et al., 2011), we demonstrated that the experimental HF cows experiencing NEB at first sampling on 1 DIM returned to positive energy balance at the day of the second-slaughter series (i.e., 42 DIM), irrespective of CLA supplementation. During early lactation, the state of NEB results in increased plasma concentrations of both NEFA and BHBA, which, in turn, exert inhibitory effects on leukocytes and, thus, contribute to the immunocompromised situation in ewes and dairy heifers (Lacetera et al., 2002, 2004). The portions of CD68+, CD14+, $\mathrm{CD} 11 \mathrm{~b}+$, and CD11c+ samples in SM heifers were consistently higher than in samples from HF cows (Table $3)$. The present data suggest that the increased accumulation of CD68+, CD14+, CD11b+, and CD11c+ cells, albeit at low cell numbers in SM heifers, could be related to large adipocytes secreting higher amounts of chemoattractant adipokines. In this context, it has 
been reported that AT production of monocyte chemoattractant protein-1, a chemoattractant specific for monocytes and macrophages is increased in obese, leptin-deficient mice compared with lean mice (Sartipy and Loskutoff, 2003). Moreover, leptin is secreted exclusively by adipocytes and is capable of linking metabolism and immune homeostasis (Matarese and La Cava, 2004). It has been reported to be also a chemoattractant for neutrophils (Ottonello et al., 2004) as well as for monocytes and macrophages (Gruen et al., 2007). In the present study, the larger adipocyte size of s.c. tailhead fat that we observed in SM heifers was associated with higher concentrations of serum leptin compared with HF cows $(P<0.05)$, with mean serum leptin concentrations of $9.14 \pm 0.23 \mathrm{ng} / \mathrm{mL}$ versus 5.33 $\pm 0.15 \mathrm{ng} / \mathrm{mL}$. However, plasma leptin concentrations may reflect increased overall secretion, but they do not provide detailed information regarding local concentration gradients formed in AT. For example, leptin is a chemoattractant at concentrations as low as $1 \mathrm{pg} / \mathrm{mL}$, with maximal effects at $1 \mathrm{ng} / \mathrm{mL}$. However chemotaxis tended to decrease at concentrations of 10 and $100 \mathrm{ng} /$ $\mathrm{mL}$ (Gruen et al., 2007). Our data also indicate that in fat RP steers, the portions of CD14+ and CD11b+ samples were higher than the HF cows, although no CD68- and CD11c-positive staining was observed in the s.c. fat in fat RP steers (Table 3). Possible reasons for this difference might be due to sex hormone differences immanent in the comparison of intact females versus male long-term castrates. Comparing intact male and female mice, Weisberg et al. (2003) reported that the portion of mature F4/80-expressing macrophages was slightly lower for the s.c. fat of males regardless of body condition.

\section{Effects of CLA on the Invasion of Phagocytic Immune Cells into Bovine AT}

In the present study, 4 positive immunostainings for CD68, CD14, CD11b, and CD11c were detected coincidently in the same tissue (s.c. tailhead) and in the same CLA-fed HF cow at 42 DIM. The same animal showed positive staining for CD68 and CD11c in the s.c. depot from the sternum at 42 DIM (Table 2). Although we hypothesized that in bovine AT, phagocytic immune cell infiltration might be affected by dietary CLA supplementation, no differences with regard to the CLA supplementation were observed in HF cows. The present study suggests that dietary CLA supplements failed to alter local environment within bovine AT during early lactation.

Several authors reported that the $t 10, c 12$ isomer promotes ATM infiltration and decreases leptin and adipo- nectin secretion, which, in turn, contributes to insulin resistance and hyperinsulinemia in CLA-fed humans and animals (Clément et al., 2002; Poirier et al., 2006; Pérez-Matute et al., 2007). The effects of CLA on adipose tissue cellularity in animals are isomer, dose, time, and species dependent. In the present study, the dose of CLA was $0.03 \%$ of the diet. Recent evidence suggests that mice receiving the $t 10, c 12$-CLA isomer at $0.5 \%$ of the diet show increased AT expression of inflammatory markers, including monocyte chemoattractant protein-1, IL-6, and TNF- $\alpha$ (Foote et al., 2010). Moreover, in vitro studies with $3 \mathrm{~T} 3-\mathrm{L} 1$ and human adipocytes have also shown that the $t 10, c 12$ isomer directly stimulates IL-6 secretion via a nuclear factor- $\kappa B$-dependent mechanism (Poirier et al., 2006). In contrast, supplementation with the $c 9, t 11$ isomer results in low ATM infiltration with concomitant decrease in inflammatory cytokines, which may, in turn, improve insulin sensitivity in mice (Moloney et al., 2007). However, the present study did not focus on the individual CLA isomers, but tested a mixture at a ratio of 50:50 for the main $c 9, t 11$ and $t 10, c 12$ isomers.

\section{CONCLUSIONS}

The portion of phagocytic immune cells both in s.c. and v.c. fat depots was marginal in early lactating cows. The average portion of ATM (CD68+) in few positive samples was slightly lower in s.c. than in v.c fat depots. No significant alterations in this infiltration phenomenon, with regard to the DIM and CLA supplementation were observed during early lactation. Increased accumulation of phagocytic immune cells, albeit at low cell numbers, in nonpregnant, overconditioned heifers could be related to larger adipocytes compared with the early lactating cows. Based on the small portion of positive samples, we concluded that the extent of fatness in early lactating dairy cows may not be high enough to stimulate significant infiltration of phagocytic cells and, therefore, these immune cells may have no major role in the immunologic and metabolic adaptations during early lactation.

\section{ACKNOWLEDGMENTS}

This research was supported by the German Research Foundation (DFG, Bonn, Germany; Grant No. PAK 286/1 and SA 432/10-1). S. H. Akter was the recipient of a Fellowship of the Islamic Development Bank (IDB) Merit Scholarship Program at the University of Bonn, Germany. We thank the manager of the Training and Research Center Frankenforst, J. Griese, and the staff for their help during the respective animal experiments. 


\section{REFERENCES}

Akter, S. H., S. Häussler, S. Dänicke, U. Müller, D. von Soosten, J. Rehage, and H. Sauerwein. 2011. Physiological and conjugated linoleic acid-induced changes of adipocyte size in different fat depots of dairy cows during early lactation. J. Dairy Sci. 94:2871-2882.

Altomonte, J., S. Harbaran, A. Richter, and H. Dong. 2003. Fat depotspecific expression of adiponectin is impaired in Zucker fatty rats. Metabolism 52:958-963.

Bauman, D. E., B. A. Corl, L. H. Baumgard, and J. M. Griinari. 2001. Conjugated linoleic acid (CLA) and the dairy cow. Pages 221-250 in Recent Advances in Animal Nutrition 2001. P. C. Garnsworthy and J. Wiseman, ed. Nottingham University Press, Nottingham, UK.

Bauman, D. E., and W. B. Currie. 1980. Partitioning of nutrients during pregnancy and lactation: A review of mechanisms involving homeostasis and homeorhesis. J. Dairy Sci. 63:1514-1529.

Bielefeldt-Ohmann, H., M. Sabara, M. J. Lawman, P. Griebel, and L. A. Babiuk. 1988. A monoclonal antibody detects macrophage maturation antigen which appears independently of class II antigen expression. Reactivity of monoclonal EBM11 with bovine macrophages. J. Immunol. 140:2201-2209.

Bouloumié, A., C. A. Curat, C. Sengenès, K. Lolmède, A. Miranville, and R. Busse. 2005. Role of macrophage tissue infiltration in metabolic diseases. Curr. Opin. Clin. Nutr. Metab. Care 8:347-354.

Brodersen, R., F. Bijlsma, K. Gori, K. T. Jensen, W. Chen, J. Dominguez, K. Haverson, P. F. Moore, A. Saalmüller, D. Sachs, W. J. Slierendrecht, C. Stokes, O. Vainio, F. Zuckermann, and B. Aasted. 1998. Analysis of the immunological cross reactivities of 213 well characterized monoclonal antibodies with specificities against various leukocyte surface antigens of human and 11 animal species. Vet. Immunol. Immunopathol. 64:1-13.

Cancello, R., C. Henegar, N. Viguerie, S. Taleb, C. Poitou, C. Rouault, M. Coupaye, V. Pelloux, D. Hugol, J.-L. Bouillot, A. Bouloumié, G. Barbatelli, S. Cinti, P.-A. Svensson, G. S. Barsh, J.-D. Zucker, A. Basdevant, D. Langin, and K. Clément. 2005. Reduction of macrophage infiltration and chemoattractant gene expression changes in white adipose tissue of morbidly obese subjects after surgery-induced weight loss. Diabetes 54:2277-2286.

Cartwright, M. J., T. Tchkonia, and J. L. Kirkland. 2007. Aging in adipocytes: Potential impact of inherent, depot-specific mechanisms. Exp. Gerontol. 42:463-471.

Cinti, S., G. Mitchell, G. Barbatelli, I. Murano, E. Ceresi, E. Faloia, S. Wang, M. Fortier, A. S. Greenberg, and M. S. Obin. 2005. Adipocyte death defines macrophage localization and function in adipose tissue of obese mice and humans. J. Lipid Res. 46:2347-2355.

Clément, K., N. Viguerie, C. Poitou, C. Carette, V. Pelloux, C. A. Curat, A. Sicard, S. Rome, A. Benis, J.-D. Zucker, H. Vidal, M. Laville, G. S. Barsh, A. Basdevant, V. Stich, R. Cancello, and D. Langin. 2004. Weight loss regulates inflammation-related genes in white adipose tissue of obese subjects. FASEB J. 18:1657-1669.

Clément, L., H. Poirier, I. Niot, V. Bocher, M. Guerre-Millo, S. Krief, B. Staels, and P. Besnard. 2002. Dietary trans-10, cis-12 conjugated linoleic acid induces hyperinsulinemia and fatty liver in the mouse. J. Lipid Res. 43:1400-1409.

Curat, C. A., A. Miranville, C. Sengenès, M. Diehl, C. Tonus, R. Busse, and A. Bouloumié. 2004. From blood monocytes to adipose tissue-resident macrophages: Induction of diapedesis by human mature adipocytes. Diabetes 53:1285-1292.

Elgazar-Carmon, V., A. Rudich, N. Hadad, and R. Levy. 2008. Neutrophils transiently infiltrate intra-abdominal fat early in the course of high-fat feeding. J. Lipid Res. 49:1894-1903.

Fain, J. N. 2006. Release of interleukins and other inflammatory cytokines by human adipose tissue is enhanced in obesity and primarily due to the nonfat cells. Vitam. Horm. 74:443-477.

Foote, M. R., S. L. Giesy, G. Bernal-Santos, D. E. Bauman, and Y. R. Boisclair. 2010. t10,c12-CLA decreases adiposity in peripubertal mice without dose-related detrimental effects on mammary development, inflammation status, and metabolism. Am. J. Physiol. Regul. Integr. Comp. Physiol. 299:R1521-R1528.
GfE (Society of Nutrition Physiology). 2001. Ausschuss für Bedarfsnormen der Gesellschaft für Ernährungsphysiologie. Nr. 8. Empfehlungen zur Energie- und Nährstoffversorgung der Milchkühe und Aufzuchtrinder (Recommendations of energy and nutrient supply for dairy cows and breeding cattle). DLG-Verlag, Frankfurt am Main, Germany.

Gordon, S., and P. R. Taylor. 2005. Monocyte and macrophage heterogeneity. Nat. Rev. Immunol. 5:953-964.

Gruen, M. L., M. M. Hao, D. W. Piston, and A. H. Hasty. 2007. Leptin requires canonical migratory signaling pathways for induction of monocyte and macrophage chemotaxis. Am. J. Physiol. Cell Physiol. 293:C1481-C1488.

Harman-Boehm, I., M. M. Blüher, H. Redel, N. Sion-Vardy, S. Ovadia, E. Avinoach, I. Shai, N. Klöting, M. Stumvoll, N. Bashan, and A. Rudich. 2007. Macrophage infiltration into omental versus subcutaneous fat across different populations: Effect of regional adiposity and the comorbidities of obesity. J. Clin. Endocrinol. Metab. 92:2240-2247.

Hotamisligil, G. S., N. S. Shargill, and B. M. Spiegelman. 1993. Adipose expression of tumor necrosis factor-alpha: Direct role in obesity-linked insulin resistance. Science 259:87-91.

Hume, D. A., I. L. Ross, S. R. Himes, R. T. Sasmono, C. A. Wells, and T. Ravasi. 2002. The mononuclear phagocyte system revisited. J. Leukoc. Biol. 72:621-627.

Khazen, W., J.-P. M'Bika, C. Tomkiewicz, C. Benelli, C. Chany, A. Achour, and C. Forest. 2005. Expression of macrophage-selective markers in human and rodent adipocytes. FEBS Lett. 579:56315634 .

Kosteli, A., E. Sugaru, G. Haemmerle, J. F. Martin, J. Lei, R. Zechner, and A. W. Ferrante Jr. 2010. Weight loss and lipolysis promote a dynamic immune response in murine adipose tissue. J. Clin. Invest. 120:3466-3479.

Lacetera, N., O. Franci, D. Scalia, U. Bernabucci, B. Ronchi, and A. Nardone. 2002. Effects of nonesterified fatty acids and betahydroxybutyrate on functions of mononuclear cells obtained from ewes. Am. J. Vet. Res. 63:414-418.

Lacetera, N., D. Scalia, O. Franci, U. Bernabucci, B. Ronchi, and A. Nardone. 2004. Short communication: Effects of nonesterified fatty acids on lymphocyte function in dairy heifers. J. Dairy Sci. $87: 1012-1014$.

Laskin, D. L. 2009. Macrophages and inflammatory mediators in chemical toxicity: A battle of forces. Chem. Res. Toxicol. 22:1376-1385.

Lumeng, C. N., S. M. Deyoung, and A. R. Saltiel. 2007. Macrophages block insulin action in adipocytes by altering expression of signaling and glucose transport proteins. Am. J. Physiol. Endocrinol. Metab. 292:E166-E174.

Mantovani, A., S. Sozzani, M. Locati, P. Allavena, and A. Sica. 2002. Macrophage polarization: Tumor-associated macrophages as a paradigm for polarized M2 mononuclear phagocytes. Trends Immunol. 23:549-555.

Matarese, G., and A. La Cava. 2004. The intricate interface between immune system and metabolism. Trends Immunol. 25:193-200.

McNamara, J. P. 2004. Research, improvement and application of mechanistic, biochemical, dynamic models of metabolism in lactating dairy cattle. Anim. Feed Sci. Technol. 112:155-176.

McNamara, J. P. 2010. Integrating transcriptomic regulation into models of nutrient metabolism in agricultural animals. Pages 27-37 in Energy and Protein Metabolism and Nutrition-EAAP Pub. No. 127. G. M. Cravetto, ed. Wageningen Academic Press, Parma, Italy.

McNamara, J. P., and J. K. Hillers. 1989. Regulation of bovine adipose tissue metabolism during lactation 5. Relationships of lipid synthesis and lipolysis with energy intake and utilization. J. Dairy Sci. 72:407-418.

Miyazawa, K., H. Aso, M. Honda, T. Kido, T. Minashima, T. Kanaya, K. Watanabe, S. Ohwada, M. T. Rose, and T. Yamaguchi. 2006. Identification of bovine dendritic cell phenotype from bovine peripheral blood. Res. Vet. Sci. 81:40-45.

Moloney, F., S. Toomey, E. Noone, A. Nugent, B. Allan, C. E. Loscher, and H. M. Roche. 2007. Antidiabetic effects of cis-9, trans-11- 
conjugated linoleic acid may be mediated via anti-inflammatory effects in white adipose tissue. Diabetes 56:574-582.

Neels, J. G., and J. M. Olefsky. 2006. Inflamed fat: What starts the fire? J. Clin. Invest. 116:33-35.

Noorman, F., E. A. M. Braat, M. Barrett-Bergshoeff, E. Barbé, A. van Leeuwen, J. Lindeman, and D. C. Rijken. 1997. Monoclonal antibodies against the human mannose receptor as a specific marker in flow cytometry and immunohistochemistry for macrophages. J. Leukoc. Biol. 61:63-72.

Ottonello, L., P. Gnerre, M. Bertolotto, M. Mancini, P. Dapino, R. Russo, G. Garibotto, T. Barreca, and F. Dallegri. 2004. Leptin as a uremic toxin interference with neutrophil chemotaxis. J. Am. Soc. Nephrol. 15:2366-2372.

Pérez-Matute, P., A. Marti, J. A. Martínez, M. P. Fernández-Otero, K. L. Stanhope, P. J. Havel, and M. J. Moreno-Aliaga. 2007. Conjugated linoleic acid inhibits glucose metabolism, leptin and adiponectin secretion in primary cultured rat adipocytes. Mol. Cell. Endocrinol. 268:50-58.

Poirier, H., J. S. Shapiro, R. J. Kim, and M. A. Lazar. 2006. Nutritional supplementation with trans-10, cis-12-conjugated linoleic acid induces inflammation of white adipose tissue. Diabetes $55: 1634-1641$

Sadri, H., R. M. Bruckmaier, H. R. Rahmani, G. R. Ghorbani, I. Morel, and H. A. van Dorland. 2010. Gene expression of tumor necrosis factor and insulin signalling-related factors in subcutaneous adipose tissue during the dry period and in early lactation in dairy cows. J. Anim. Physiol. Anim. Nutr. (Berl.) 94:e194-e202.

Saillan-Barreau, C., B. Cousin, M. André, P. Villena, L. Casteilla, and L. Pénicaud. 2003. Human adipose cells as candidates in defense and tissue remodeling phenomena. Biochem. Biophys. Res. Commun. 309:502-505.

Sartipy, P., and D. J. Loskutoff. 2003. Monocyte chemoattractant protein 1 in obesity and insulin resistance. Proc. Natl. Acad. Sci USA 100:7265-7270.

Sauerwein, H., U. Heintges, M. Hennies, T. Selhorst, and A. Daxenberger. 2004. Growth hormone induced alterations of leptin serum concentrations in dairy cows as measured by a novel enzyme immunoassay. Livest. Prod. Sci. 87:189-195.

Schäffler, A., and J. Schölmerich. 2010. Innate immunity and adipose tissue biology. Trends Immunol. 31:228-235.
Schymeinsky, J., A. Mócsai, and B. Walzog. 2007. Neutrophil activation via $\beta_{2}$ integrins (CD11/CD18): Molecular mechanisms and clinical implications. Thromb. Haemost. 98:262-273.

Skurk, T., C. Herder, I. Kräft, S. Müller-Scholze, H. Hauner, and H. Kolb. 2005. Production and release of macrophage migration inhibitory factor from human adipocytes. Endocrinology 146:10061011.

Smith, D. J., and J. P. McNamara. 1989. Lipolytic response of bovine adipose tissue to alpha and beta adrenergic agents 30 days preand 120 days postpartum. Gen. Pharmacol. 20:369-374.

Smith, T. R., and J. P. McNamara. 1990. Regulation of bovine adipose tissue metabolism during lactation. 6. Cellularity and hormonesensitive lipase activity as affected by genetic merit and energy intake. J. Dairy Sci. 73:772-783.

SPSS Inc. 2010. Advanced Statistics. Version 19.0. SPSS Inc., Chicago, IL.

von Soosten, D., U. Meyer, E. M. Weber, J. Rehage, G. Flachowsky, and S. Dänicke. 2011. Effect of trans-10, cis-12 conjugated linoleic acid on performance, adipose depot weights, and liver weight in early-lactation dairy cows. J. Dairy Sci. 94:2859-2870.

Weisberg, S. P., D. McCann, M. Desai, M. Rosenbaum, R. L. Leibel, and A. W. Ferrante Jr. 2003. Obesity is associated with macrophage accumulation in adipose tissue. J. Clin. Invest. 112:17961808.

Wellen, K. E., and G. S. Hotamisligil. 2005. Inflammation, stress, and diabetes. J. Clin. Invest. 115:1111-1119.

Xu, H., G. T. Barnes, Q. Yang, G. Tan, D. Yang, C. J. Chou, J. Sole, A. Nichols, J. S. Ross, L. A. Tartaglia, and H. Chen. 2003. Chronic inflammation in fat plays a crucial role in the development of obesity-related insulin resistance. J. Clin. Invest. 112:1821-1830.

Zeyda, M., D. Farmer, J. Todoric, O. Aszmann, M. Speiser, G. Györi, G. J. Zlabinger, and T. M. Stulnig. 2007. Human adipose tissue macrophage are of an anti-inflammatory phenotypes but capable of excessive pro-inflammatory mediator production. Int. J. Obes. (Lond.) 31:1420-1428.

Zeyda, M., and T. M. Stulnig. 2007. Adipose tissue macrophage. Immunol. Lett. 112:61-67. 